\title{
Performance Characteristics of a Small Poppet Valve Crankshaft Engine in Free- Piston Engine Mode
}

\author{
M. Razali Hanipah 1,2, ${ }^{*}$ and M. Haziq Adham Rosli1 \\ ${ }^{1}$ Department of Mechanical Engineering, College of Engineering, Universiti Malaysia Pahang, 26300 Gambang, Pahang, Malaysia \\ 2Automotive Engineering Centre, Universiti Malaysia Pahang, 26600 Pekan, Pahang, Malaysia
}

\begin{abstract}
The free-piston engine generator (FPEG) provides a novel method for electrical power generation in the range extender and hybrid electric vehicle application. In this paper, onedimensional (1D) numerical simulations of a two-stroke poppet valve in crankshaft engine (CSE) and free-piston engine (FPE) modes are presented to illuminate the potential performance gain of a two-stroke poppet valve engine for free-piston engine generator application. The 1D numerical simulation for crankshaft and free-piston engine models focuses on the two-stroke engine performance response. Both models were subjected to variations of ignition and valve timings. The impact of lambda on engine performance was obtained. Finally, a single speed of $3000 \mathrm{rpm}$ was chosen for detail performance behaviour of the free-piston engine model response. The results have shown that the CSE model has demonstrated traditional performance behaviour against ignition timing variation. In addition, FPE model performance is highly affected by both intake and exhaust valve timings as compared to the CSE model. Furthermore, CSE is superior to FPE across lambda variations for BSFC, brake thermal efficiency, brake power and bmep. These models have successfully portrayed realistic engine performance response as presented in the lambda variations simulation. When simulated at an intended operating speed of $50 \mathrm{~Hz}$, the FPE model has shown poorer performance. The bmep and brake power of FPE model dropped by $3 \%$, brake thermal efficiency dropped by $26 \%$, and BSFC increased by $21 \%$. This lower performance is attributed by $30 \%$ reduction in piston velocity suffers in FPE, which contributed to $13 \%$ reduction in peak cylinder pressure. Ignition delays promote better FPE performance which is able to match the CSE model. In conclusion, this paper has demonstrated the performance behaviour of a twostroke free-piston engine model based on the baseline crankshaft engine model.
\end{abstract}

ARTICLE HISTORY

Received: $26^{\text {th }}$ Jan 2021

Revised: $14^{\text {th }}$ Oct 2021

Accepted: 22 ${ }^{\text {nd }}$ Oct 2021

\section{KEYWORDS}

Free-piston engine; Crankshaft engine;

Two-stroke poppet valve; One-dimensional simulation; Engine performance

\section{INTRODUCTION}

The free-piston engine generator (FPEG) concept is still full of challenges as well as prospects for future applications [1] and has attracted commercial interests (for review, see Hanipah et al. [2]). In recent years, the successful introduction of electric vehicles by various manufacturers, especially Tesla, Chevrolet and Nissan, shifted the focus away from FPEG potential as an alternative vehicle powertrain. The advantage of an FPEG for electric vehicle range-extenders or hybrid powertrain is mainly because the combustion events can be controlled using the integrated electric machine, as demonstrated in a proof-of-concept prototype [3]. A free-piston engine works on the principle of dynamic forces which produces linear reciprocation motion. Such an engine is said to be dynamically constrained as opposed to a kinematically constrained crank-slider engine [4]. Dynamically constrained means the piston stop positions (TDC and BDC) are not constant, and its motion profile is not governed by any mechanical component as in the crankshaft engine. However, the FPEG system requires intervention for sustainable operation through motion control strategies [5].

The performance of a crankshaft engine is measured using a dynamometer which gives torque and power at various engine speeds for various loads at maximum brake torque (MBT) [6]. In addition, indicated thermal efficiency is calculated from the pressure-volume diagram and while brake thermal efficiency is determined from the measured brake power off the crankshaft using a dynamometer. Ideally, the performance of a crankshaft engine can be represented by torque and power curves versus engine speed as well as brake thermal efficiency. These performance characteristics will be evaluated at optimised exhaust emissions and fuel conversion efficiency. On the contrary, a free-piston engine generator produces no useful torque to be measured. Its performance can be represented through indicated thermal efficiency as well as electrical power generation efficiency.

The researchers in Sandia National Laboratory [7, 8] have conducted a numerical study and a series of single-shot experiments. Due to ideal Otto cycle behaviour demonstrated through the rapid compression expansion machine (RCEM) experiments, it is possible to achieve an indicated thermal efficiency of 56\% with low emissions and a very lean (fuel/air equivalence ratio of 0.35 ) fuel/air mixture at a high compression ratio (30:1) [8]. A free-piston energy converter (FPEC) was investigated in the Royal Institute of Technology (KTH). The FPEC was designed for the application of Hybrid 
Electric Vehicle (HEV) with $45 \mathrm{~kW}$ power output capacity. Through MATLAB-Simulink modelling, the efficiency was found to perform around $10 \%$ better than diesel electrical generators at $10-20 \mathrm{~kW}$ load and 5\% at 20-40 kW load [9].

The researchers from Chalmers University of Technology had simulated the FPEC piston dynamic using MATLABSimulink, the gas exchange was calculated using BOOST, and the chemistry was simulated in SENKIN. The overall efficiency of the FPEC (fuel-to-electricity) was found to range from 41.9 to $44.4 \%$ (assuming $50 \%$ frictional loss on valve actuation and 95\% electrical efficiency) [10]. Further, an HCCI free piston energy converter (FPEC) developed for vehicle propulsion was shown numerically to achieve an indicated efficiency of $51 \%$ at $23 \mathrm{~kW}$ load power [11].

A spark ignition (SI) and compression ignition (CI) free piston generator were investigated by Mikalsen and Roskilly $[12,13]$ via computer simulations. Both models were generated using $\mathrm{C}++$ and implemented in OpenFOAM. The ignition timing of the spark-ignited engine was optimised at maximum brake torque (MBT). The indicated thermal efficiency of the free-piston generator was higher than the conventional engine at lower engine speed (below $3000 \mathrm{rpm}$ ) found to be peaked at $32.6 \%$ [13]. The CI version was simulated in HCCI mode and has achieved almost $50 \%$ indicated thermal efficiency [12]. Researchers from Nanjing University had tested a linear generator integrated power system and successfully obtained $32 \%$ electrical generating efficiency as opposed to only $20 \%$ achieved by conventional generators with similar specifications. The numerical simulation results had shown $42 \%$ generating efficiency [14].

In summary, previous research works have highlighted the performance advantage of a free-piston engine. In this paper, one-dimensional models of two-stroke poppet valve in crankshaft engine (CSE) and free-piston engine (FPE) modes are presented to illuminate the potential performance gain of a two-stroke poppet valve engine for free-piston engine generator application, which is currently under development in Universiti Malaysia Pahang.

\section{ENGINE SPECIFICATIONS AND MODEL CONSTRUCTION}

One-dimensional (1D) modelling of an internal combustion engine is one step beyond standard engine thermodynamic analyses. The coding comprises fundamental thermodynamics equations and empirical relationships which are able to simulate the overall engine behaviour sufficiently to provide preliminary performance and emissions characteristics of an engine under development. A 1D modelling and simulation tool is used for engine development by major automotive companies to assist prototype development due to its capability to produce realistic results quickly. Further, it requires less overhead cost and computational cost without the need for three-dimensional computer-aided design (CAD) design of the engine. Table 1 shows the engine specifications for the baseline model construction. The base engine is a $65 \mathrm{cc}$, four-stroke gasoline-fuelled, designed for garden portable machinery applications capable of achieving high power and torque with low emission [15]. It has $50 \mathrm{~mm}$ bore and $33 \mathrm{~mm}$ stroke with a 9.5:1 compression ratio. The intake and exhaust valve diameters are $20 \mathrm{~mm}$ and $18 \mathrm{~mm}$ respectively, with both having a similar maximum valve lift of $3.2 \mathrm{~mm}$.

Table 1. The baseline engine specifications.

\begin{tabular}{lc}
\hline Parameter & Value \\
\hline Capacity $\left(\mathrm{cm}^{3}\right)$ & 65 \\
Bore $(\mathrm{mm})$ & 50 \\
Stroke $(\mathrm{mm})$ & 33 \\
Geometric compression ratio $(-)$ & $9.5: 1$ \\
Valve lift $(\mathrm{mm})$ & 3.2 \\
Intake valve diameter $(\mathrm{mm})$ & 20 \\
Exhaust valve diameter $(\mathrm{mm})$ & 18 \\
\hline
\end{tabular}

\section{Numerical Model Construction}

The whole process of one-dimensional numerical model construction is summarised in Figure 1. The first step in the 1D internal combustion engine model involves the construction of five main subsystems, namely, the intake and exhaust ports and valves and the cylinder component. Then, relevant geometric data are entered in each subsystem to define the engine characteristics as obtained from the manufacturer datasheet and measurements. Finally, the baseline operating parameters of the engine are determined, which involve engine speed range, fuel type, air-fuel ratio and ambient conditions definitions.

The engine specifications in both simulation models used for the performance investigation are summarised in Table 2. Both models used the same parameters and valves timings except that for the free-piston engine, the crank angle degree $\left({ }^{\circ} \mathrm{CA}\right)$ represented the equivalence angle as the piston motion is not governed by the same crank/slider sub-model. The stroke was increased to $38 \mathrm{~mm}$ nominal for added safety clearance from valves at maximum lifts, which could potentially hit the piston at TDC. At $4 \mathrm{~mm}$ of clearance distance, these models compression ratio is 10.5:1. Similar valve timings were used initially before valve timing optimisations were conducted, which have been done in previous work [16]. Similarly, the sub-models employed in both models, as shown in Table 3, are similar except for the piston motion where the free-piston engine was governed by the user-defined function (UDF) sub-model. 

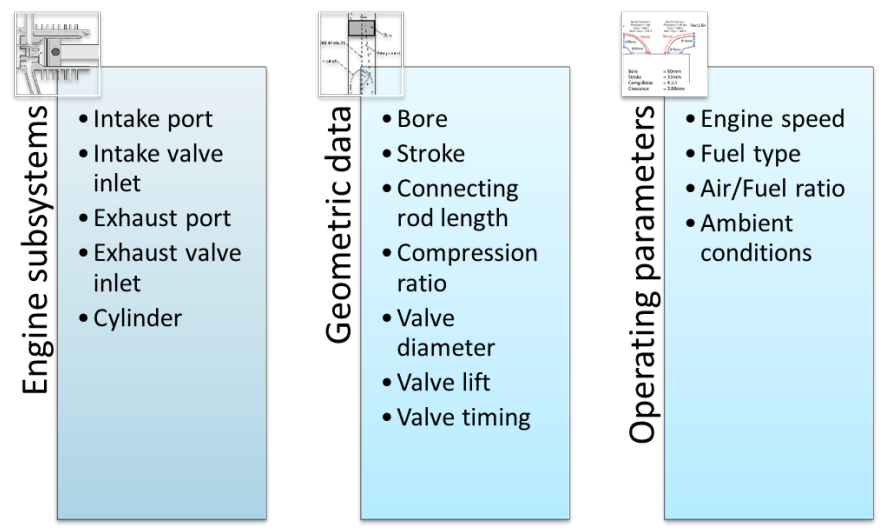

Figure 1. The procedure of one-dimensional numerical simulation.

Table 2. The engine specifications used for developing the crankshaft vs free-piston engine performance investigation.

\begin{tabular}{lcc}
\hline & Crankshaft engine (CSE) & Free-piston engine (FPE) \\
\hline Bore $(\mathrm{mm})$ & 50.0 & 50.0 \\
Stroke $(\mathrm{mm})$ & 38.0 & 38.0 (Nominal) \\
CR $(\mathrm{l})$ & $10.5: 1$ & $10.5: 1$ (Nominal) \\
Valve lift $(\mathrm{mm})$ & 4 & 4 \\
Inlet valve diameter $(\mathrm{mm})$ & 16.5 & 16.5 \\
Exhaust valve diameter $(\mathrm{mm})$ & 18.5 & 18.5 \\
Intake valve open/close $\left({ }^{\circ} \mathrm{CA}\right)$ & $140 / 230$ & $140 / 230$ (Equivalent angle) \\
Exhaust valve open/close $\left({ }^{\circ} \mathrm{CA}\right)$ & $105 / 225$ & $105 / 225$ (Equivalent angle) \\
Clearance height $(\mathrm{mm})$ & 4.0 & 4.0 \\
\hline
\end{tabular}

Table 3. Sub-models employed the simulation models.

\begin{tabular}{lcc}
\hline Sub-models & Crankshaft engine (CSE) & Free-piston engine (FPE) \\
\hline Primary combustion & SI-Wiebe & SI-Wiebe \\
Zones & Two & Two \\
Heat transfer & Woschni original & Woschni original \\
Injector & Proportional & Proportional \\
Friction & Chen-Flynn friction & Chen-Flynn friction \\
Knock & Douaud and Eyzat model & Douaud and Eyzat model \\
Scavenging & Fully mix & Fully mix \\
Piston motion & Crank/slider & User-defined \\
\hline
\end{tabular}

\section{RESULTS AND DISCUSSION}

This section presents the 1D numerical simulation results for crankshaft and free-piston engine models focusing on the two-stroke engine performance response. Both models were subjected to variations of ignition and valve timings. The impact of lambda on engine performance was obtained. Finally, the single-speed of $3000 \mathrm{rpm}$ was chosen for detailed performance behaviour of free-piston engine model response

Torque is an important performance parameter for a crankshaft engine that reflects the engine's ability to do work and can be obtained from engine dynamometer testing $[6,17,18]$. However, the free-piston engine does not produce torque since there is no crankshaft. Therefore, in this research, bmep were used for assessing torque producing capability of both models. The combustion in an SI engine starts shortly after the ignition point, and the target is typically to get the maximum cylinder pressure at around $5^{\circ}$ to $20^{\circ}$ after TDC [19]. While in the numerical models, the location of $50 \%$ mass fraction burned is used as the variable for representing the ignition position in model response investigations.

\section{Crankshaft Engine Model Response Sensitivity on Ignition Timing}

Figure 2(a) shows the impact of ignition timing (CA50) on the two-stroke crankshaft engine brake power. The maximum brake power is concentrated between $-5^{\circ}$ and $25^{\circ}$ with a corresponding engine speed range between 3000 and $5000 \mathrm{rpm}$. Figure 2(b) shows the maximum CSE brake mean effective pressure (bmep) occurs at an earlier engine speed range between 1000 to $2500 \mathrm{rpm}$; this is known as low-end torque, occurs when the CA50 range is from $5^{\circ}$ to $30^{\circ}$.

Brake thermal efficiency map, as shown in Figure 2(c), indicates that the engine is most efficient between 4000 and $5000 \mathrm{rpm}$ with ignition timing between 0 and $15^{\circ}$. This information was used to conduct an optimisation for obtaining the best maximum brake torque (MBT) timing for both models. 


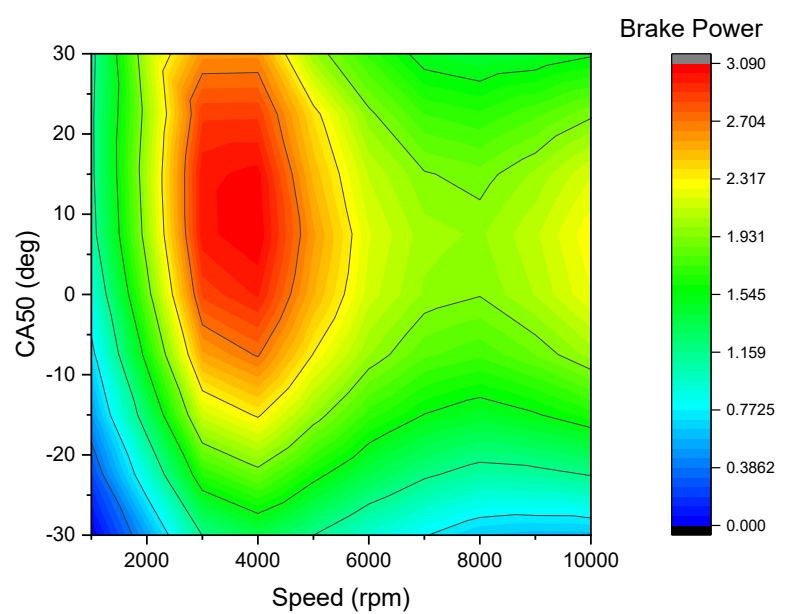

(a)

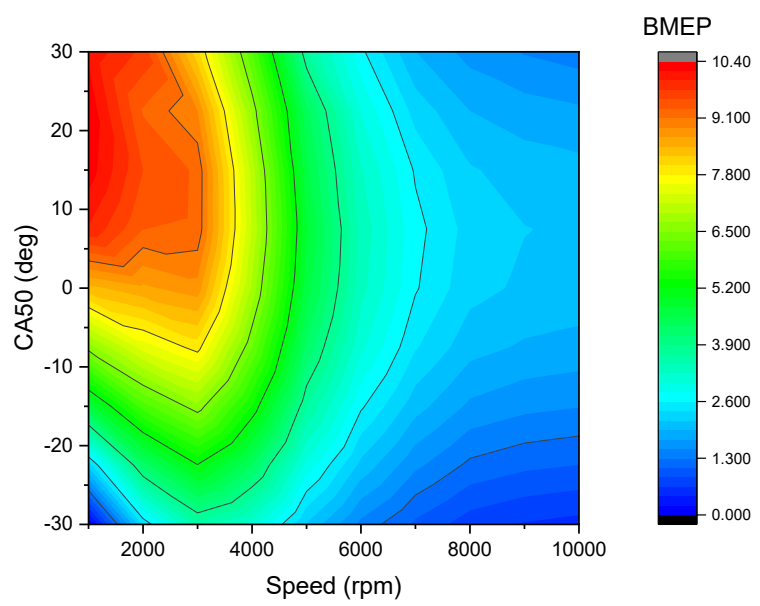

(b)

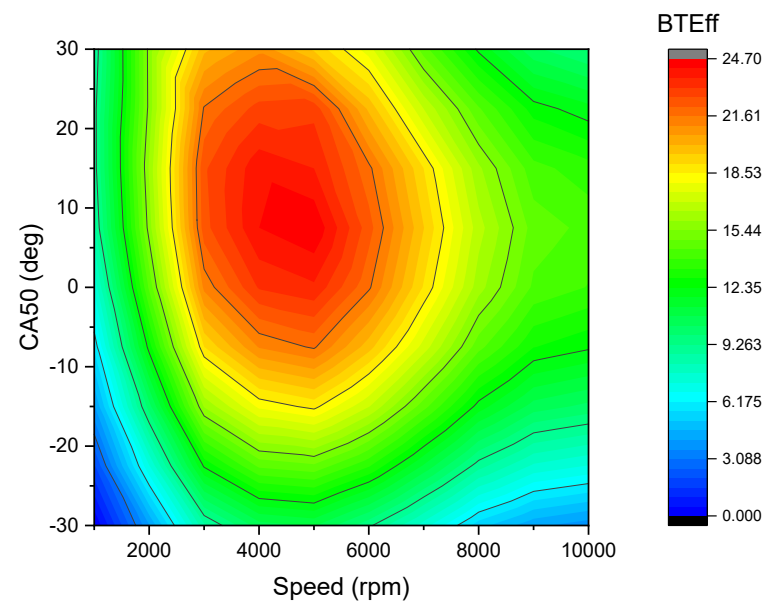

(c)

Figure 2. The impact of ignition timing on engine (a) brake power, (b) bmep and (c) brake thermal efficiency of the two-stroke crankshaft engine.

\section{Model Response Sensitivity on Intake and Exhaust Valves Timings}

Besides ignition timing, intake and exhaust valve timings are also affected engine performance behaviour. Figure 3 shows engine bmep contour in response to the variation of the opening crank angle degree position of both intake and exhaust valves. The red zones indicate the highest bmep, which is a desirable characteristic. The free-piston engine model, as shown in Figure 3(a), indicates favourable early valve opening positions between 130 to $140^{\circ}$ for exhaust and 160 to $165^{\circ}$ for intake. On the other hand, the crankshaft engine model shows the best response at $150^{\circ}$ for exhaust and 175 to $185^{\circ}$ for intake opening positions. A similar response for engine brake power is observed in Figure 4 for both models.

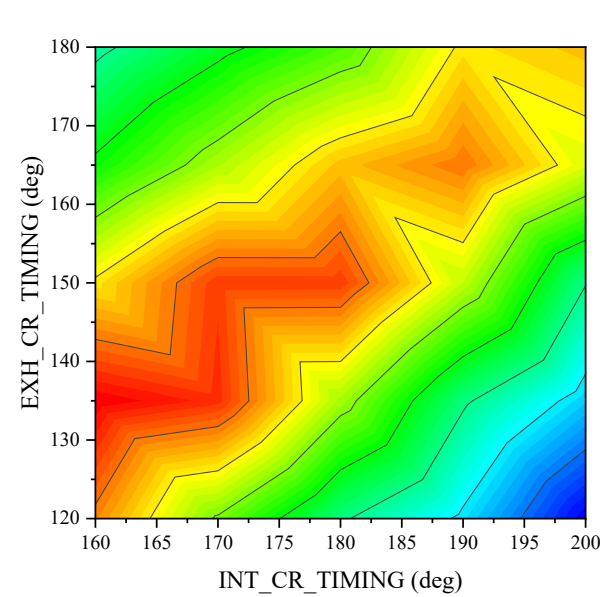

(a)

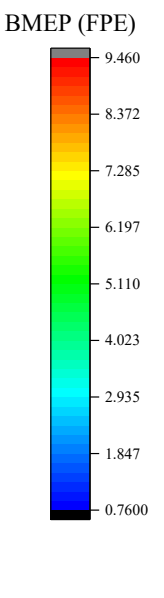

Figure 3. The impact of intake and exhaust valve timings on bmep for (a) free-piston engine and (b) crankshaft engine.

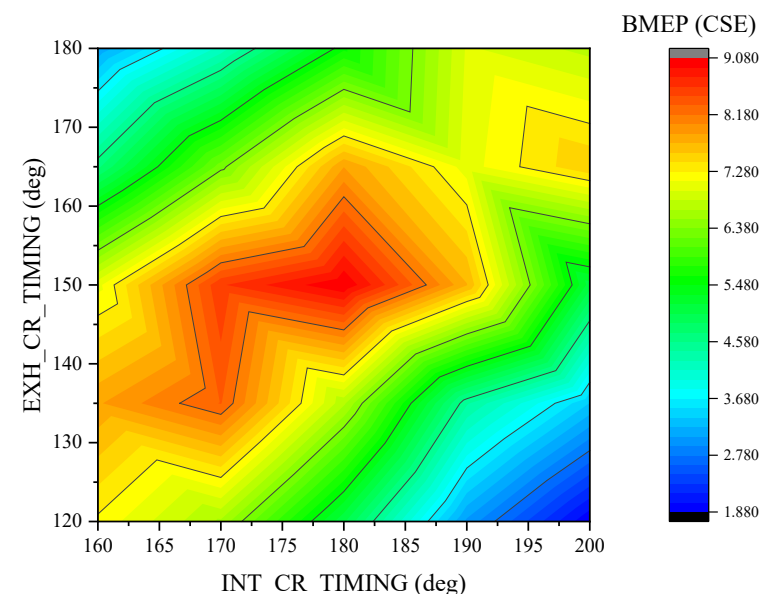

(b) 


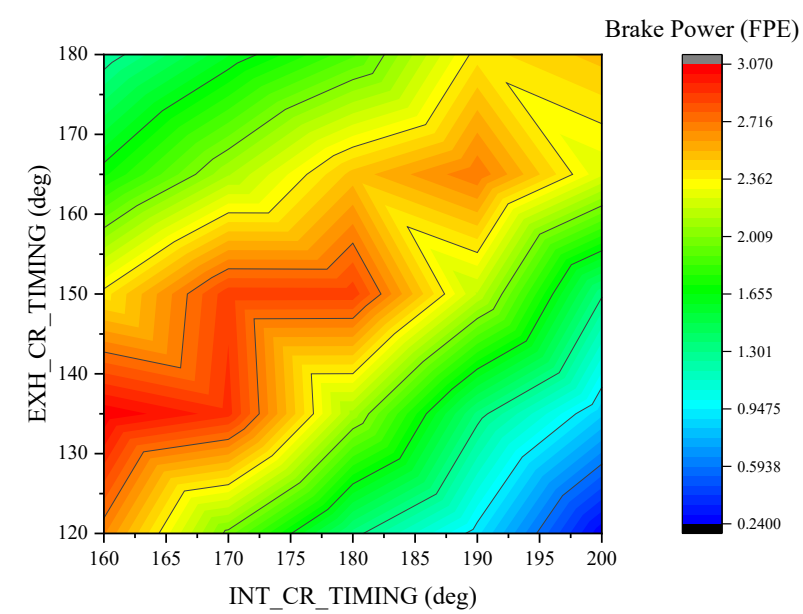

(a)

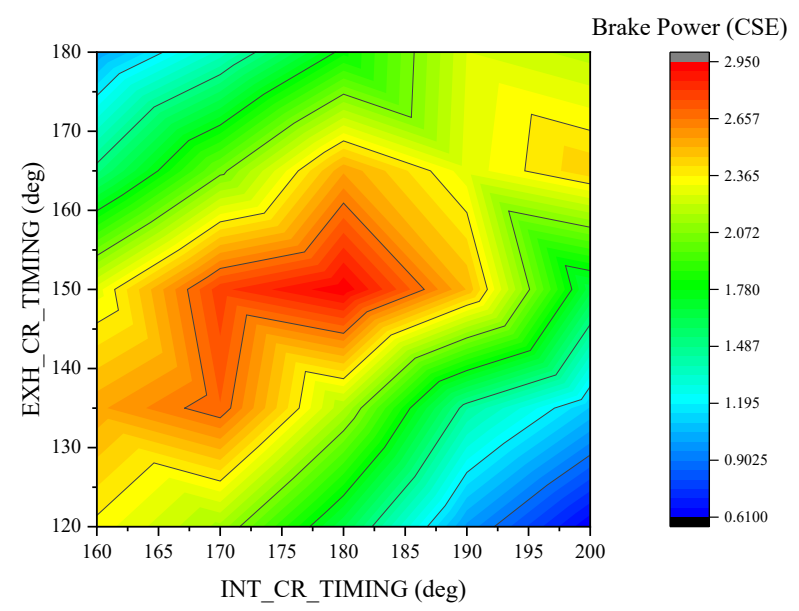

(b)

Figure 4. The impact of intake and exhaust valve timings on brake power for (a) free-piston engine and (b) crankshaft engine.

Brake thermal efficiency contour response for FPE demonstrates two distinct islands centralised at $150^{\circ}$ and $180^{\circ}$ for exhaust, as shown in Figure 5. A wider efficiency island is observed for the CSE model across the whole range intake opening crank angle pivoted at $150^{\circ}$ exhaust opening. In summary, several optimised settings were found through the optimisation of ignition points and valve timings. In the following section, these models were subjected to lambda variations from lean to rich mixtures.

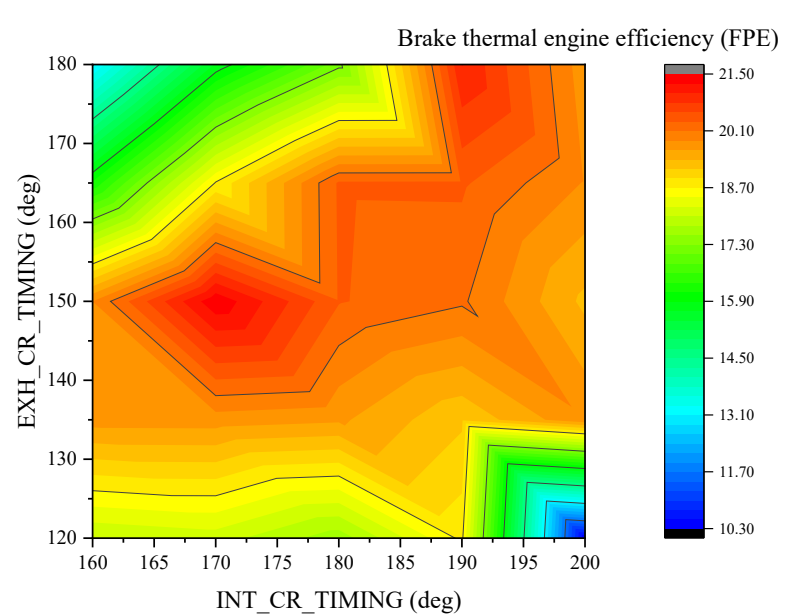

(a)

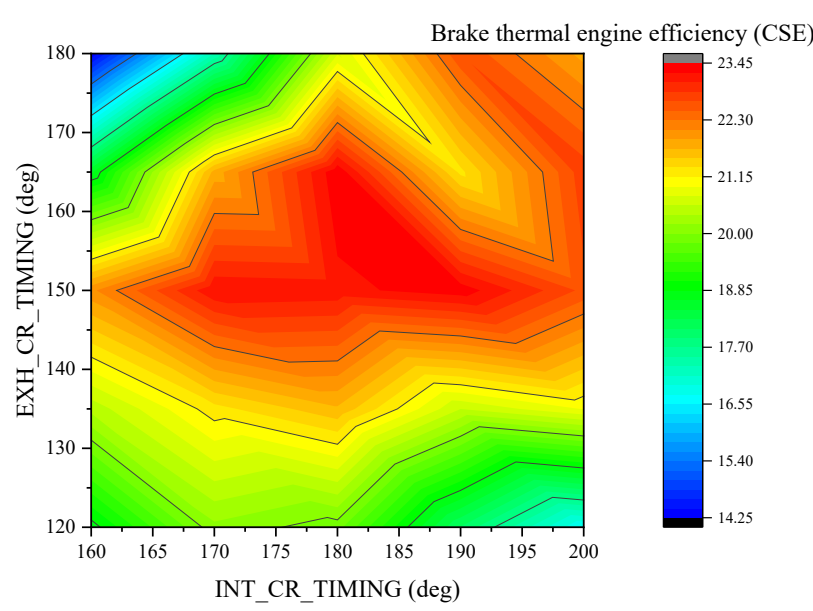

(b)

Figure 5. The impact of intake and exhaust valve timings on brake power for (a) free-piston engine and (b) crankshaft engine.

\section{The Impact of Lambda Engine Performance}

Several optimised settings were found through the optimisation of ignition points and valve timings. The model response on lambda variations is shown in Figure 6, it can be observed that the CSE model has shown better performance than the FPE model as illustrated in BSFC, brake thermal efficiency, brake power and bmep.

The validation of these results can be verified through the plot in Figure 7, which shows typical BSFC and brake power performance response against lambda. The leaner mixture gives the best brake power output, as depicted in Heywood [6]. This verified that the models had behaved realistically to produce these results. These models have successfully portrayed realistic engine performance responses as presented in the lambda variations simulation. Furthermore, an optimum setting must be obtained at every engine operating regime by looking at the maximum power and lowest BSFC while varying the ignition timing. The next section focuses on a single-speed comprehensive evaluation of both models. 


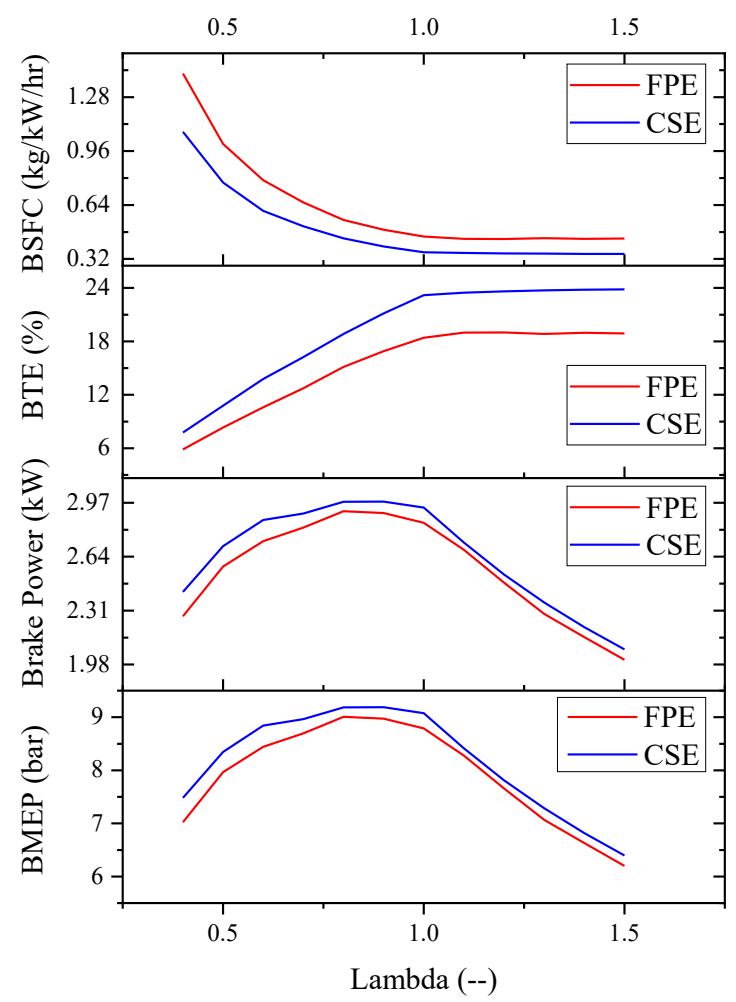

Figure 6. The impact of lambda on engine performance parameters for free-piston engine and crankshaft engine.

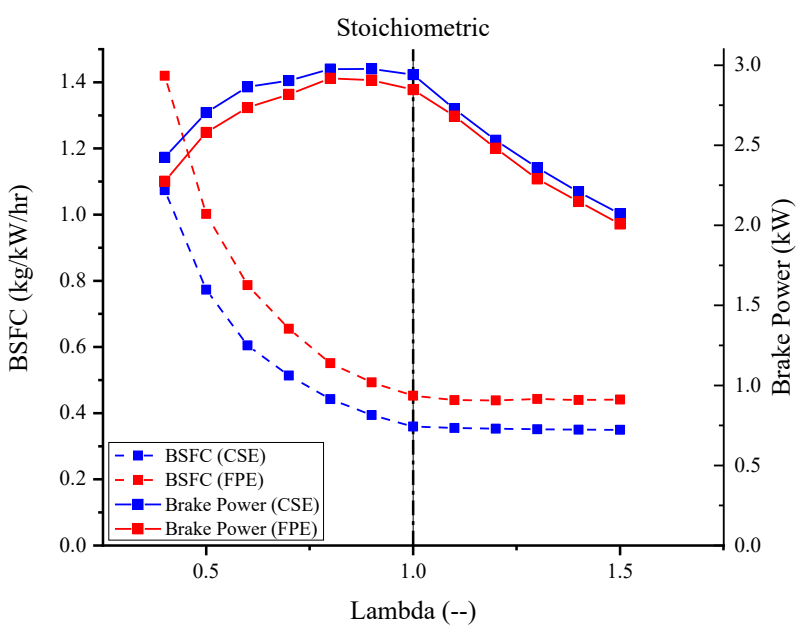

Figure 7. The impact of lambda on engine performance parameters for free-piston engine and crankshaft engine.

\section{Two-stroke Engine Performance at 3000 rpm (CSE vs FPE)}

As the FPE is aimed for power generators for series hybrid vehicles, a single speed of $50 \mathrm{~Hz}$ (equivalent to $3000 \mathrm{rpm}$ ) has been identified as the optimum speed of operation as reported previously [16]. Figure 8 shows the performance characteristics for both CSE and FPE models at $50 \mathrm{~Hz}$. In all aspects, the FPE model has shown poorer performance. The bmep and brake power of the FPE model dropped by $3 \%$, brake thermal efficiency dropped by $26 \%$ and BSFC increased by $21 \%$.

In order to understand the cause of this performance reduction in FPE, in-cylinder pressure at $50 \mathrm{~Hz}$ are plotted as shown in Figure 9. The cylinder pressure development during compression in FPE is slower, resulting 13\% lower peak pressure, which is achieved $1 \mathrm{~ms}$ later than CSE as observed in Figure 9(a). Regardless, when plotted in crank-angle based pressure, both engines are developing at the same crank angle, as shown in Figure 9(b).

The slower rate of cylinder pressure development is attributed to $30 \%$ reduction in piston velocity in FPE although running at a similar cyclic speed of $50 \mathrm{~Hz}$, as shown in Figure 10(a). The lower piston velocity in FPE is due to its intrinsic nature of oscillation without any hindrance from the crank-slider mechanism, which governs the piston motion in CSE. 

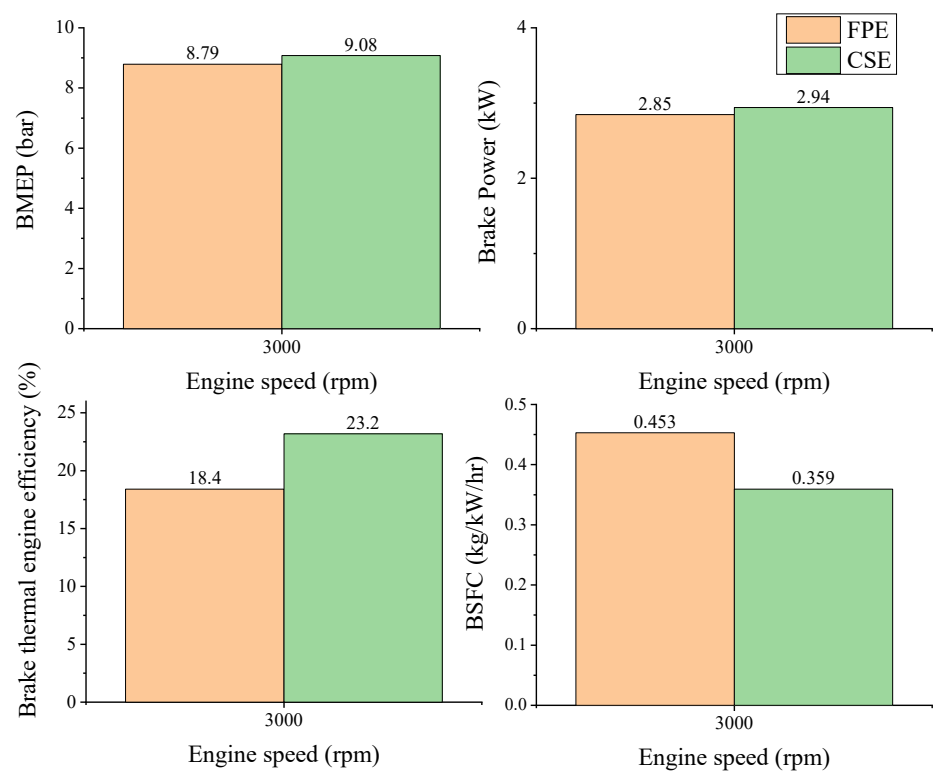

Figure 8. The engine performance at an optimum operational speed of 50Hz (3000rpm).

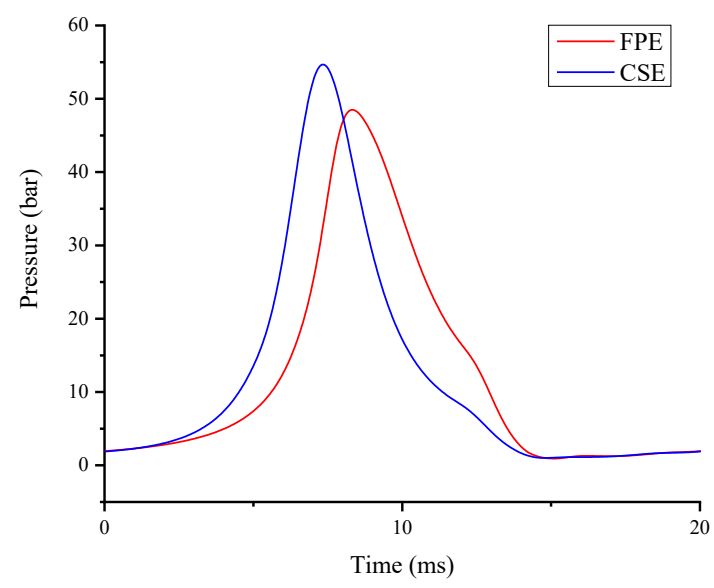

(a) time-based

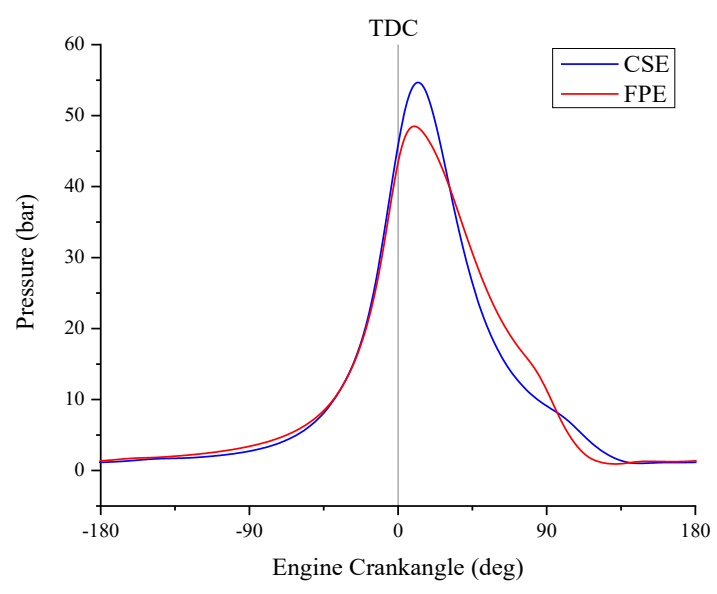

(b) crank-angle based

Figure 9. The in-cylinder pressure development for FPE and CSE.

\section{Engine Performance Tuning at 3000 rpm (CSE vs FPE)}

Further performance tuning was done to observe model response on the ignition timings. Figure 11 shows the performance response for CSE and FPE models, which illustrates how ignition timing affects the performance parameters. At $-20^{\circ}$ ignition point, each brake power and bmep for CSE model are $71 \%$ and $55 \%$ more than FPE model while brake thermal efficiency is $54 \%$ more. Meanwhile, at $20^{\circ}$ and $30^{\circ}$ ignition points, these differences were reduced to zero, indicating that the ignition delays promote better FPE engine performance.

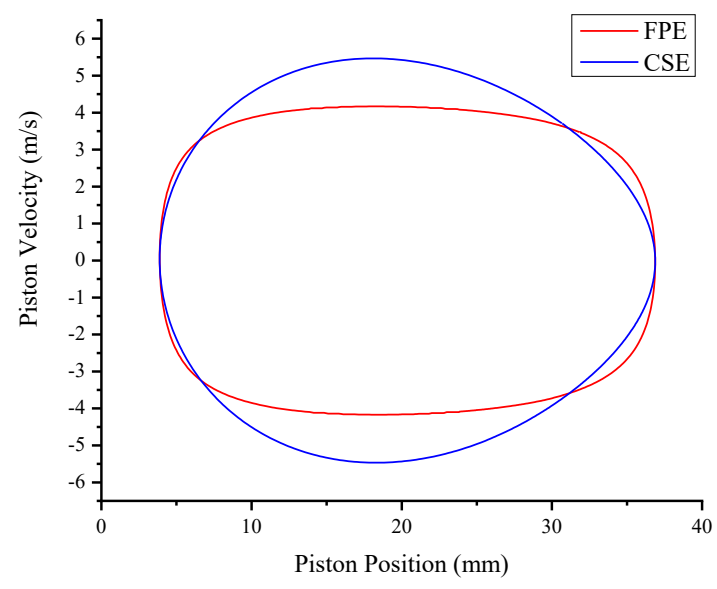

(a)

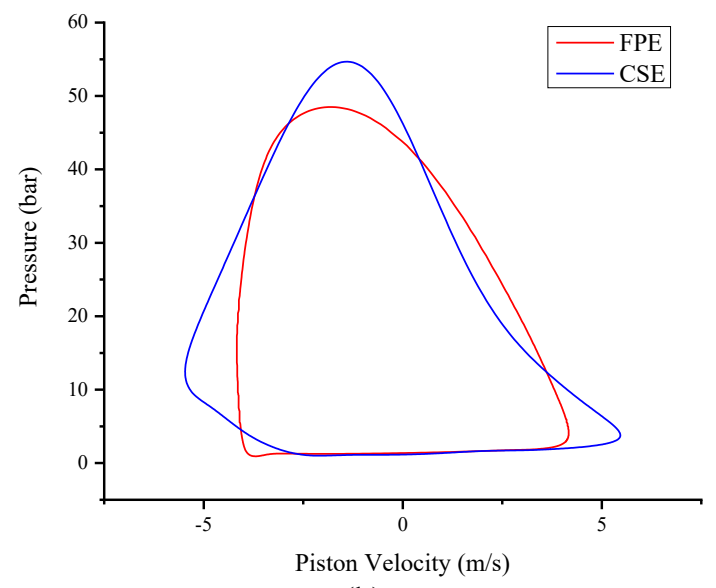

(b)

Figure 10. (a) Piston velocity vs piston position and (b) pressure vs piston velocity for FPE and CSE at $50 \mathrm{~Hz}$ (3000rpm). 


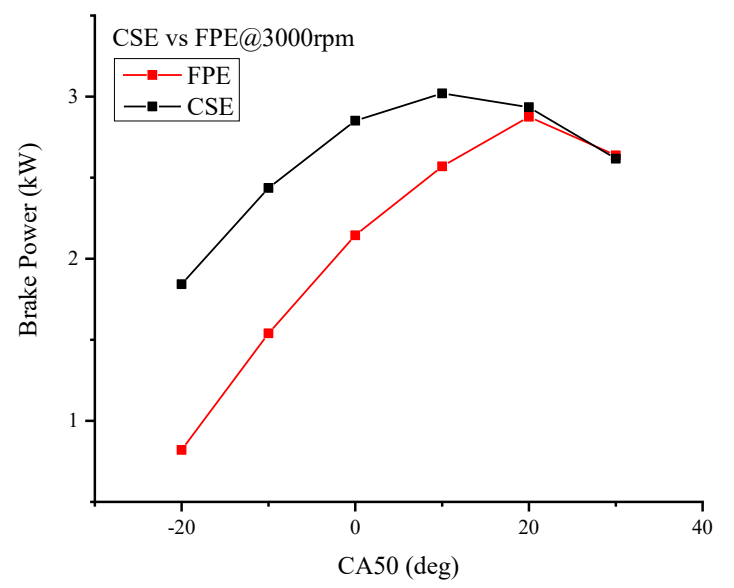

(a)

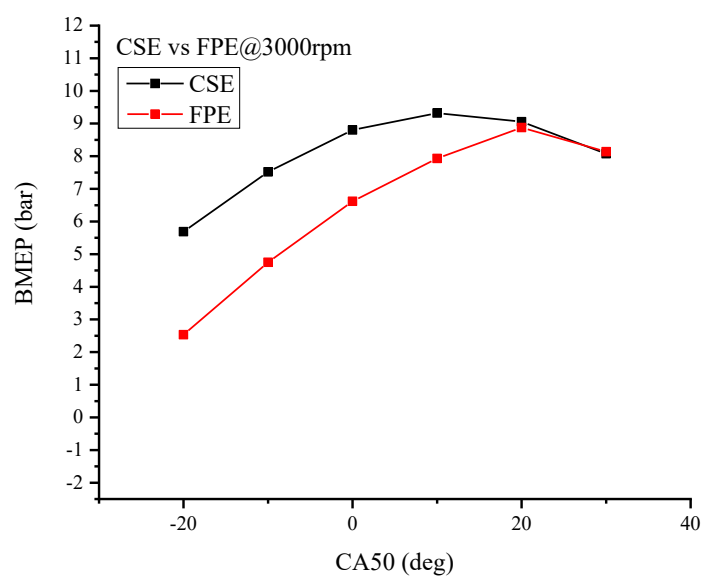

(b)

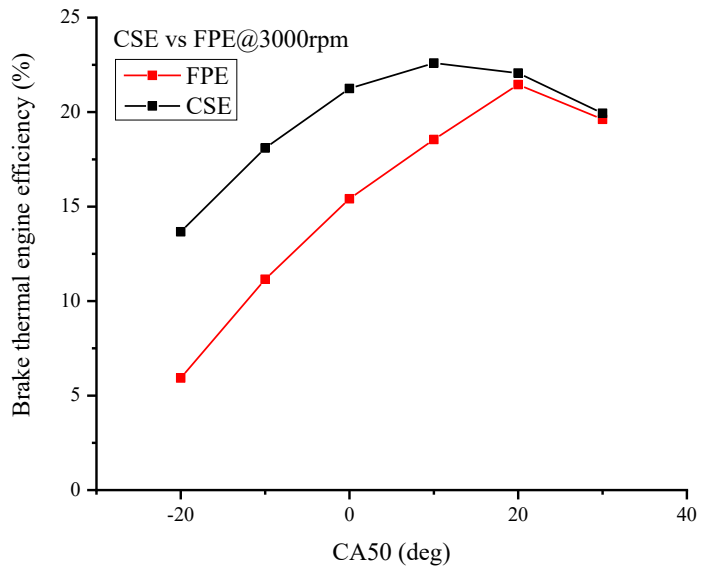

(c)

Figure 11. The impact of ignition timings on engine performance parameters for FPE and CSE.

\section{CONCLUSION}

This paper has presented 1D numerical simulation for CSE and FPE models, and the following conclusions are obtained:

i. The CSE model has demonstrated traditional performance behaviour against ignition timing variation. This is concluded based on the performance response for the CSE model as a result of ignition timing variations obtained as follows:

ii. Maximum brake power occurs between 3000 and $5000 \mathrm{rpm}$ with ignition timing between $-5^{\circ}$ and $25^{\circ}$ while maximum bmep occurs between 1000 to $2500 \mathrm{rpm}$ when the ignition timing is between $5^{\circ}$ and $30^{\circ}$. Brake thermal efficiency is maximum between 4000 to $5000 \mathrm{rpm}$ with ignition timing between $0^{\circ}$ and $15^{\circ}$.

iii. FPE model performance is highly affected by both intake and exhaust valve timings compared to the CSE model. The performance response for CSE and FPE models as a result of intake and exhaust valves timing variations obtained as follows:

iv. In terms of bmep and brake power, the FPE model indicates favourable early valve opening positions $130^{\circ}$ to $140^{\circ}$ for exhaust and $160^{\circ}$ to $165^{\circ}$ for intake whereas the CSE model shows the best response at $150^{\circ}$ for exhaust and $175^{\circ}$ to $185^{\circ}$ for intake. In terms of brake thermal efficiency, the FPE model demonstrates two distinct islands centralised at exhaust opening positions of $150^{\circ}$ and $180^{\circ}$ across the whole intake opening crank angle. A wider efficiency island is observed for the CSE model across the whole range intake opening crank angle pivoted at $150^{\circ}$ exhaust opening.

v. CSE is superior to FPE across lambda variations for BSFC, brake thermal efficiency, brake power and bmep. These models have successfully portrayed realistic engine performance responses as presented in the lambda variations simulation. Furthermore, an optimum setting must be obtained at every engine operating regime by looking at the maximum power and lowest BSFC while varying the ignition timing.

vi. When simulated at an intended operating speed of $50 \mathrm{~Hz}$, the FPE model has shown poorer performance. The bmep and brake power of the FPE model dropped by $3 \%$, brake thermal efficiency dropped by $26 \%$, and BSFC increased by $21 \%$. This lower performance is attributed by $30 \%$ reduction in piston velocity suffers in FPE, which contributed to $13 \%$ reduction in peak cylinder pressure. 
vii. Ignition delays promote better FPE performance which is able to match the CSE model. This model has illustrated how the spark ignition version of FPE is preferable since the ignition points can be controlled precisely.

\section{ACKNOWLEDGEMENT}

The authors would like to thank the Ministry of Higher Education Malaysia for providing research grant under reference code FRGS/1/2018/TK10/UMP/02/11 and Universiti Malaysia Pahang (http://www.ump.edu.my/) for grant RDU1903102 and providing laboratory facilities.

\section{REFERENCES}

[1] C. Guo et al., "Review of recent advances of free-piston internal combustion engine linear generator," Appl. Energy, vol. 269, 115084, 2020, doi: 10.1016/j.apenergy.2020.115084.

[2] M.R. Hanipah, R. Mikalsen, and A.P. Roskilly, "Recent commercial free-piston engine developments for automotive applications", Appl. Therm. Eng., vol. 75, pp. 493-503, 2015, doi: 10.1016/j.applthermaleng.2014.09.039.

[3] A. Smallbone et al., "The realisation of a novel free-piston engine generator for hybrid electric-vehicle applications", Energy \& Fuels, vol. 34, no. 10, 2020, doi: 10.1021/acs.energyfuels.0c01647.

[4] H.T. Aichlmayr, "Design considerations, modeling and analysis of micro-homogeneous charge compression ignition combustion free-piston engines," PhD thesis, University of Minnesota, USA, 2002.

[5] M.R. Hanipah, and R. Akhtar Razul, "The numerical assessment of motion strategies for integrated linear motor during starting of a free-piston engine generator", IOP Conference Series: Materials Science and Engineering, vol. 257, no. 1, 2017, doi: $10.1088 / 1757-899 X / 257 / 1 / 012054$.

[6] J.B. Heywood, Internal Combustion Engine Fundamentals, McGraw-Hill International, 1988.

[7] S.S. Goldsborough, and P.V. Blarigan, "A numerical study of a free piston IC engine operating on homogeneous charge compression ignition combustion," SAE International 1999-01-0619, 1999.

[8] P.V. Blarigan, N. Paradiso, and S.S. Goldsborough, "Homogeneous charge compression ignition with a free piston: a new approach to ideal otto cycle performance", SAE International 982484, 1998.

[9] P. Brejaud et al., "One dimensional modeling and experimental validation of single cylinder pneumatic combustion hybrid engine”, SAE Int. J. Engines, vol. 4, no. 2, p. 2326-2337, 2011, doi: 10.4271/2011-24-0074.

[10] J. Fredriksson, and I. Denbratt, "Simulation of a two-stroke free piston engine," SAE International 2004-01-1871, 2004.

[11] M. Erland, "Free piston energy converter," EVS21, In Proceedings of the 21st Electric Vehicle Symposium \& Exhibition, Monaco, 2005.

[12] R. Mikalsen, and A.P. Roskilly, "The design and simulation of a two-stroke free-piston compression ignition engine for electrical power generation”, Appl. Therm. Eng., vol. 28, no. 5-6, p. 589-600, 2008, doi: 10.1016/j.applthermaleng.2007.04.009.

[13] R. Mikalsen, and A.P. Roskilly, "Performance simulation of a spark ignited free-piston engine generator", Appl. Therm. Eng., vol. 28, no. 14-15, pp. 1726-1733, 2008, doi: 10.1016/j.applthermaleng.2007.11.015.

[14] Z. Xu, and S. Chang, "Prototype testing and analysis of a novel internal combustion linear generator integrated power system", Appl. Energy, vol. 87, no. 4, pp. 1342-1348, 2010 ,doi: 10.1016/j.apenergy.2009.08.027.

[15] A.S. AG, 4-MIX engine: Lightweight and with good lugging power, 2014. [Online]. Available: http://www.stihl.com/4-mixengine-lightweight-and-with-good-lugging-power.aspx. [Accessed: Nov. 17, 2014].

[16] M.R. Hanipah, "Development of a spark ignition free-piston engine generator," PhD thesis, Newcastle University, Newcastle upon Tyne, United Kingdom, 2015.

[17] W.W. Pulkrabek, Engineering fundamentals of the internal combustion engine, Prentice-Hall, Inc.1997.

[18] G.P. Blair, Design and simulation of two-stroke engines, SAE Inc., Warrendale, PA, 1996.

[19] R. Stone, Introduction to internal combustion engines, Third Edition ed., Society of Automotive Engineers, Inc., Warrendale, Pa., 1999. 